\title{
Correction to: Spectroscopic and electrochemical properties of PVP based polymer electrolyte films
}

\section{S. K. Shahenoor Basha ${ }^{1}$ - M. C. Rao ${ }^{2}$}

Published online: 17 June 2019

(c) Springer-Verlag GmbH Germany, part of Springer Nature 2019

\section{Correction to: Polym. Bull. (2018) 75:3641-3666 \\ https://doi.org/10.1007/s00289-017-2229-2}

This erratum corrects the Figs. 1 and 2e of the published paper. The results presented in the published paper are correct and are not affected by the change in figures.

The authors regret for the change in Figures.

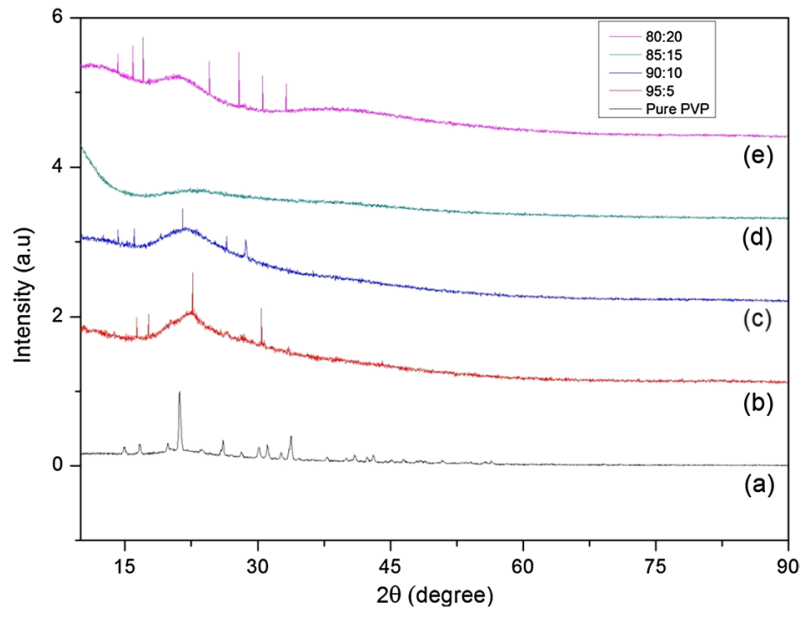

Fig. 1 XRD analysis of polymer electrolyte films for different wt\% ratios of a Pure PVP, b (95:5), c (90:10), d (85:15) and e (80:20)

The original article can be found online at https://doi.org/10.1007/s00289-017-2229-2.

M. C. Rao

raomc72@gmail.com

1 Solid State Ionics Laboratory, Department of Physics, K. L. University, Guntur 522502, India

2 Department of Physics, Andhra Loyola College, Vijayawada, Andhra Pradesh 520 008, India 


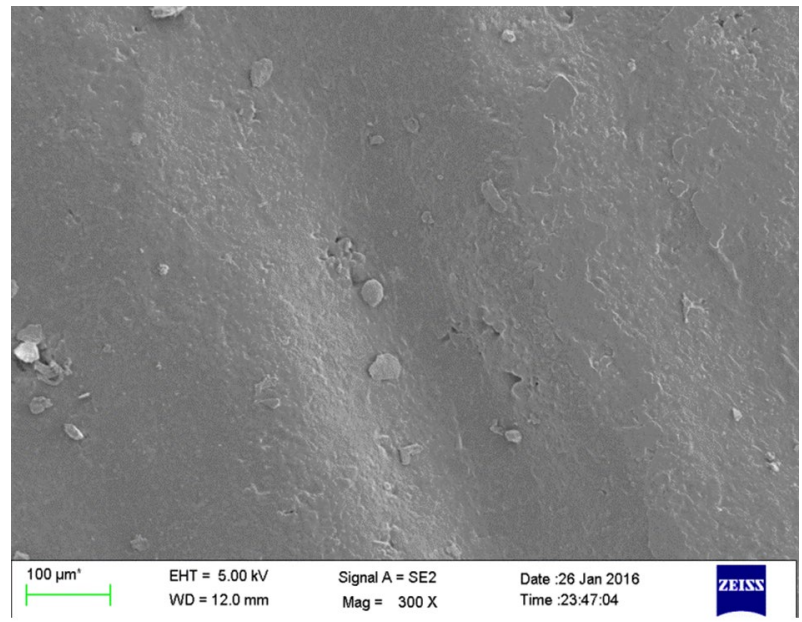

(e)

Fig. 2 e SEM image of polymer electrolyte film for e (80:20) wt $\%$ ratios of SPE

Publisher's Note Springer Nature remains neutral with regard to jurisdictional claims in published maps and institutional affiliations. 